\title{
The Reform and Practice of the Cultivation Mode for the Mechanical Specialty Aimed at the Innovation Ability
}

\author{
TANG BO \\ School of Machinery and Automation \\ Wuhan University of Science and Technology \\ Wuhan, China
}

\author{
HOU YU \\ School of Machinery and Automation \\ Wuhan University of Science and Technology \\ Wuhan, China
}

\begin{abstract}
In the light of some problems existing in personnel cultivation mode and course examination for mechanical specialty in colleges and universities, and also "Internet plus" has brought the challenge to higher education and opportunities, the seminar class teaching method is developed, blended teaching means is discussed, integration practice for course is established, and diversified examination evaluation reform is explored. Through these teaching reform, the college students' interest in learning is stimulated, the students' individualized learning and active learning are achieved, and their innovation ability are also improved.
\end{abstract}

Keywords—personnel cultivation model; seminar class teaching method; Mechanical specialty; Examination reform

\section{INTRODUCTION}

"Internet Plus" and "industry 4.0" representing a new round of industrial revolution, put forward a challenge to traditional mode of personnel cultivation.

In the past, the pattern of large-scale personnel cultivation from the curriculum system, teaching content planning, practice content to the examination method has not adapted to the needs of diversified personnel cultivation, and has encountered unprecedented challenges.

In order to explore the cultivation methods and ways of mechanical professionals in depth, it is of great theoretical and practical significance to improve the quality of personnel cultivation by taking the reform of classroom teaching, practice and evaluation methods as the core. The main research and exploration of teaching problems include:

(1) To solve the problems of traditional teaching mode, the students' creative thinking and spirit are promoted and the effect of classroom teaching is improved through the topic-based classroom teaching.

(2) In the light of the isolation and the deficiency of the practice, the practical teaching mode is researched, thus the transfer from engineering knowledge to engineering ability and train the engineering talents with comprehensive quality and innovation ability are realized.

(3)According to the single form of curriculum assessment and the disjunction with the cultivation goal, the diversified evaluation and evaluation system based on process is designed, and the diversity, research and openness of the examination method are highlighted, and then teaching level and the personnel cultivation quality are improved oriented by the reform of curriculum examination oriented.

\section{The MEANS AND METHODS FOR TEACHING IN "INTERNET PluS"}

\section{A. MOOC and Microlearning}

"Internet plus" is a new generation of Internet technology based on the information revolution, and it has also brought the revolutionary impact and challenge to the idea of higher education, which promotes the teaching content, method, model and teaching management system have undergone profound changes. MOOC and microlearning are generated under this background.

MOOC stands for massive open online course, which is an online course aimed at unlimited participation and open access via the web [1]. MOOC integrates a variety of social networking tools and a variety of forms of digital resources, and has got a wide range of learning tools and a wealth of curriculum resources. In addition to traditional course materials such as filmed lectures, readings, and problem sets, many MOOCs provide interactive user forums to support community interactions among students, professors, and teaching assistants. MOOCs are a recent and widely researched development in distance education which were first introduced in 2008 and emerged as a popular mode of learning in 2012. According to The New York Times, 2012 became "the year of the MOOC" as several well-financed providers, associated with top universities, emerged, including Coursera, Udacity, and $\operatorname{edX}[2][3]$.

Although there has been access to free online courses on the Internet for years, the quality and quantity of courses has changed.

MOOC has the outstanding characteristic of open, and breaks through the limitation of time and space of traditional courses. The learner of the Internet all over the world can learn the famous university course at home and abroad through MOOC. On the other hand, MOOC course has a higher enrollment rate, but also has a higher dropout rate, which requires learners to have a strong self-learning ability to complete the course content on time. 
Microlearning deals with relatively small learning units and short-term learning activities. More frequently, the term is used in the domain of e-learning and related fields in the sense of a new paradigmatic perspective on learning processes in mediated environments. In a wider sense, microlearning is a term that can be used to describe the way more and more people are actually doing informal learning and gaining knowledge in micro-content, micromedia or multitasking environments (microcosm), especially those that become increasingly based on Web 2.0 and wireless web technologies. In this wider sense, the borders between microlearning and the complementary concept of microknowledge are blurring [4].

Microlearning processes often derive from interaction with microcontent, which takes place either in designed (media) settings (e-learning) or in emergent micro content structures like weblog postings or social bookmark managers on the World Wide Web.Microlearning can be an assumption about the time needed to solve a learning task, for example answering a question, memorizing an information item, or finding a needed resource [5].

With the rapid development of multimedia, Both MOOC and Microlearning have brought innovation to the traditional teaching method, which has brought vitality to the traditional classroom.

\section{B. Seminar Teaching Method}

In order to solve the contradiction between the rapid development of higher education and teaching resources are relatively tight, the common method is using large classes. Because of the number of college students in large classes, the main teaching method is lectured by teacher mainly, and it is difficult to good interact and communicate between teachers and students, so it is not easy to conducive the students' initiative. In order to solve this problem, the teaching method of seminar class model is developed.

There are three levels of teaching team in the seminar class discussion. The teaching team consists of class lecture teachers, seminar class teachers and teaching assistants. The lecture teachers are responsible for teaching curriculum theory system and knowledge structure. Each seminar class with 2-3 young teachers guiding students to discuss and study, thus the dominant position of students is highlighted and college students' initiative and enthusiasm are aroused. The assistants are responsible for checking the homework and helping to solve the problems such as simulation, production, programming and so on.

There have three steps of the seminar discussion. The process of seminar discussion based on the theme of tasks is divided into three stages: First, teachers publish research tasks, the second is the college students self-learning, division of labor and complete tasks, the third is a small class discussion and comment summary.

The work submitted by the small class study can be based on the analysis of the report, self-programming, design reports, product production, research reports or any other form of display, in order to give full play to the initiative of college students, creativity and personality.

\section{Blended Teaching Method}

Blended Learning refers to the combination of online learning and traditional learning mode, which can improve the learning interest and learning engagement of students, and enhance the curriculum challenges, then help to improve teaching quality, achieve better teaching.

Online learning is mainly based on students' learning. As the main target for early guidance, some of the key and difficult content are provided students to preview or review. Students can also be provided some expansion of learning content. Mainly through the MOOC to provide students with a complete system of learning.

In classroom, teacher can reduces teaching content, and increases seminar discussion. Seminar discussion can adapt to the level of knowledge of students as a starting point, allowing students to analyze and think, until the solution is put to an end. Through this learning process, the students' thinking ability, autonomous learning ability, as well as the participation of teaching is also significantly improved, so as to achieve a better learning effect.

The Blended teaching will change the teacher centered teaching method into the learner centered autonomous learning mode. The online learning let learners grasp the basic learning content and construct the knowledge structure; line classroom teaching emphasis on building the import and the system of knowledge, solve the key and difficult topic; On the other hand, seminar discussion emphasizes the application of knowledge and ability training. The combination of online and offline teaching mode has become an effective way to improve the quality of teaching and learning.

\section{REFORM OF PRACTICE TEACHING METHOD BASED ON INTEGRATED MEANS}

\section{A. Principles of Practice Teaching Reform}

There are some shortcomings in the traditional practice for mechanical curriculum. First, most of the curriculum experiments are demonstration and verification, which the college students experiment in accordance with the inherent procedures, so independent thinking space for college students is very limited. Second, curriculum design is obsolete, thus college students innovative ability is difficult to form. Third, the single form of practice assessment cannot reflect the personality differences of college students. Last, practice management model is rigid, which cannot keep up with the pace of development of the times. The 
reform of practice teaching is guided by the idea of "three combinations", that is, the combination of classroom teaching and experimental teaching, the combination of real experiment and virtual experiment, and the combination of in-class experiment and open experiment.

Student can apply for the content of the projects to replace the existing curriculum design content in accordance with the direction of interest, which carry out the projects in the curriculum of mechanical principles design, professional curriculum design, and even graduation design combined with innovative experiments.

At the same time combined with the innovative experiments, practice training and discipline competition to expand and extend the practice teaching.

Through the integration, optimization and integration of the project, it can promote the integration of the knowledge system, and realize the transfer from the engineering knowledge to the engineering ability, and cultivate the college students ' comprehensive quality and engineering innovation ability.

\section{B. Practice Teaching Method Based on Integrated Means}

With the academic research project as the driving force and relying on the tutorial system to open up the curriculum design, innovation experiment, enterprise practice, graduation design practice, thus complete the practice training. The practice project comes from teachers' scientific research projects, the college students complete the modeling analysis and theoretical calculation in curriculum design, then complete the revision of the understanding of knowledge and solutions in the enterprise on-site training. In their thesis to complete the summary of research results, thus gain the complete research and cultivation. The final outcome of the project is to publish scientific research papers or apply for invention patents.

With the innovative design project as the driving and relying on the "college students' innovation workshop" to open up the curriculum design, innovation experiments and discipline competition, and then the college students will gain a complete engineering design and product development training.

According to contest topic design goals, the students complete the creative design of mechanism schemes in mechanical principle course design, structural parts design in mechanical design curriculum design. Next, the simulation and real production, assembly and adjustment will be completed in the "college students' innovation workshop". In the process of competition students also need to design documentation and presentation PPT, and reply or on-site operation。 The whole process strengthens the integration of knowledge, and enhances the ability of linking, synthesis and optimization. The final result of the project is to complete the physical works and win the prize.

In addition, with the application of engineering projects as the driving force and relying on the establishment of multi-level joint training and practice base to joint curriculum design, practice and training, graduation design practice. Under the guidance of college and university teachers, in view of the practical problems of enterprise production, engineering design, manufacturing, management and service are integrated

\section{METHODS FOR DIVERSIFIED EXAMINATION REFORM}

\section{A. Diversified and Dynamic Forms of Examination}

The form of examination should break through the single form of "classroom plus test" in the past. The diversified examination form is an important condition for stimulating college students ' interest in learning and improving learning efficiency. It is also a concrete external manifestation of scientific teaching and examination. The diversity of test forms can be reflected in the combination of closed-book examinations and open-book examinations, the combination of process examinations and final examinations, the combination of optional actions and mandatory actions, and the combination of informal examinations and formal examinations. Examination can also be a combination of design practice and theoretical analysis, combination of written examination and oral defense, and combination of independent thinking and teamwork combined [6].

Dynamic examination is an important means to strengthen the teaching process guidance and management, scientific evaluation of college students learning effect, and it is also an important way to strengthen the comprehensive ability of college students.

\section{B. Diversity and Process of Examination Evaluation}

The traditional course scores are generally given by "final theory test plus usual results". The usual performance is a combination of the course assignments, attendance and (or) experimental test scores, which is a small proportion of the course score. The establishment of a diversified examination and evaluation mechanism, not only complement each other with the content of the scientific examination and diverse forms of examination, but also the basis for the reform of the examination content and form.

The emphasis of the diversified examination evaluation is to increase the proportion of college students' achievements in many aspects, pay attention to the assessment of the learning process, and eliminate the phenomenon that the students are usually slack but temporary study just before final exam. 
According to the learning situation of the college students, meeting the needs of different learning levels, interests and talents cultivation needs. Final course score is combination of "mandatory content" and "choice content". The former mainly consists of mid-term test score, final exam score and the stages of the test scores, experiment performance, homework, etc. The latter can be selected from several major categories, such as investigation report, experimental training, programming, software application, product design and production, extracurricular science and technology activities. According to the specific situation, the teacher gives the weight of each part of the work, and finally gives the total score.

\section{Specific Measures for Examination Reform}

In view of the professional courses, examination will be divided into two types: basic examination and comprehensive examination. Basic examination includes graduation examination, stages test. Comprehensive examination includes interview, experiment, seminar, special defense, research design, professional research projects, analysis report, scientific research, and engineering practice. The examination content for professional elective courses is wide with flexible assessment methods. The professional elective courses, or to open exam courses job examination, examination content is wide, flexible assessment methods.

The mechanical principle course as an example, the assessment methods and results is made up of test score of per month which proportion is a total score of $30 \%$, assignments and attendance accounted for $20 \%$, Course Project, including modeling innovative design or mechanism motion simulation, programming mechanism, is total score of $30 \%$, the final exam score accounted for $20 \%$. Mechanical principle experiment set up a separate course, its score is given according to the overall completion of the experiments.

Based on the process of diversification assessment method that guided by the cultivation of college students' comprehensive ability, to promote the transformation of the process examination. Both the design of the content and the means of the assessment reflect the scientific and comprehensive, and give full play to the function of the evaluation and evaluation system, thus promote the overall improvement of the level of teaching and learning.

\section{CONCLUSION}

Today, with the progress of science and technology change rapidly and increasingly fierce competition for people, China is also facing the grim task of building an innovative country, requiring higher education to cultivate college students' comprehensive quality and innovation ability. Under these circumstances, traditional methods and teaching content face severe challenges. Therefore, we must reform the teaching methods and examination means as a starting point and a breakthrough, then carry out all of the reforms for teaching content, teaching methods, teaching materials, teaching practice and teaching management reform, and then create favorable conditions for the cultivation of innovative talents.

In the process of cultivation of mechanical engineering professionals, Colleges and universities should be based on the development of students' personality and the characteristics of the school to develop appropriate teaching objectives. This training should be diverse, in order to develop the potential and ability of different individuals.

With engineering ability and innovation ability as the goal of comprehensive reform of teaching content, teaching method and practice system, realize the goals that have diversification of cultivating, flexible of curriculum system, personalized teaching methods, differentiation of practice teaching, and diversification of evaluation methods. Reform and practice in Mechanical specialty in Wuhan University of Science and Technology has achieved initial results.

There is no limit to the teaching reform, so we will continue to work hard to continue to explore the mode of personnel cultivation, and constantly cultivate the innovation ability of college students, and extend the results of the reform to a larger range.

\section{ACKNOWLEDGMENT}

This research was financially supported by the Teaching research project of Hubei Provincial Department of Education (No. 2016231 and 2014219).

\section{REFERENCES}

[1] A. M. Kaplan and H.Michael. Higher education and the digital revolution: About MOOCs, SPOCs, social media, and the Cookie Monster. Business Horizons. Vol.59 (2016), No.4, p.441.

[2] Lewin and Tamar (20 February 2013). Universities Abroad Join Partnerships on the Web. New York Times. Retrieved 6 March 2013.

[3] P. Laura. The Year of the MOOC. The New York Times. Retrieved, 18, April, 2014.

[4] Information on https://en.m.wikipedia.org/wiki/Microlearning.

[5] Mosel and Stephan: Self Directed Learning With Personal Publishing and Microcontent. Constructivist Approach and Insights for Institutional Implementations. Paper presented at the Microlearning 2005 conference, Austria. 2005, June.pp 23-24.

[6] G.Z.Jiang, B.Tang, Y.Hou, G.M.Zou and G.F.Li.Research on the Reform of examination and evaluation system for the course of mechanical major in Colleges and Universities. University Education. (2016), No.5, p.138. 